\title{
A STUDY OF EVALUATION OF LOCAL INFILTRATION OF BOTULINUM TOXIN AS COMPARED TO LATERAL SPHINCTEROTOMY IN THE MANAGEMENT OF CHRONIC ANAL FISSURE
}

\author{
Ravindranath Singh ${ }^{1}$, Puneet Pal Singh Oberoi ${ }^{2}$, Nisith Kumar Ray ${ }^{3}$ \\ ${ }^{1}$ Assistant Professor, Department of General Surgery, MVJMC \& RH. \\ 2 Post Graduate, Department of General Surgery, MVJMC \& RH. \\ 3 Professor \& HOD, Department of General Surgery, MVJMC \& RH.
}

\begin{abstract}
OBJECTIVES AND AIM

Chronic anal fissure is a common condition presenting to surgical OPD. The treatment for Anal Fissure is based on reducing the spasm of the internal anal sphincter, by use of local anesthetics, by muscle relaxation with the help of chemical sphincterotomy or surgical sphincterotomy. Analysis of the available literature shows that medical manipulation of the internal sphincter should be the first-line treatment in Anal Fissure. A surgical therapy is called for if the medical therapy fails or there is a recurrence.

The treatment for Anal Fissure is based on reducing the spasm of the internal anal sphincter by dilating the anal canal and breaking this vicious cycle and this can be achieved by 2 methods.

a) Surgical: Lateral Internal Sphincterotomy. It is a surgical technique to cure Anal Fissure. It has been favored by most of the surgeons, because it offers long-lasting relief in sphincter spasm. Lateral Internal Sphincterotomy is considered as the gold standard treatment for chronic fissures, but it permanently weakens the internal sphincter and may lead to anal deformity and incontinence in 8-30\% of patients. Therefore, recently nonsurgical treatment modalities have come to the forefront.

b) Non-Surgical: Smooth muscle relaxation is an effective non-surgical treatment for Chronic Anal Fissure and has advantages over surgical treatment in avoiding long-term complications. Additionally, it does not require hospitalization. Smooth muscle relaxation is also the first option in patients with a high risk of incontinence. Smooth muscle relaxation has been tried using a variety of agents, e.g., Glyceryl Trinitrate (GTN) and Botulinum Toxin (BTX).
\end{abstract}

This study is to see the role of Botulinum Toxin (A smooth muscle relaxant) in non-surgical management of Chronic Anal Fissure.

\section{Materials and Methods:}

Source of Data: All cases of chronic fissure in ano from OPD and patients admitted in surgical ward of M V J Medical College And Research Hospital.

Method of Collection of Data: The study was done for 60 cases with chronic anal fissure, and was divided in two groups at random. An informed consent was taken from the patient.

1. Study Cases received single injections of Botulinum toxin type A purified neurotoxin complex (BOTOX), which is available in a sterile, vacuum dried form of purified Botulinum type A produced from a culture of a Hall strain of clostridium Botulinum growth in medium containing- $Z$ amine and yeast extract.

2. Control cases underwent lateral internal sphincterotomy (LIS) done under spinal/general anesthesia.

\section{Inclusion Criteria:}

Patients were accepted on the basis of at least one of the following criteria:

1. History of symptoms more than 3 months (Bleeding per rectum, pain during defecation and itching etc.)

2. Induration of edges of fissure with no edema/inflammation.

3. Sentinel pile.

4. Hypertrophied anal papilla.

\section{Exclusion Criteria:}

1. Children below 12 years of age.

2. Pregnant women.

3. Patients having associated diseases like haemorrhoids/fistula in ano/abscess.

4. Patients who have had previous operation of the anal canal.

5. Diabetics.

6. Patients above 70 years of age.

7. Immunocompromised (AIDS).

\section{KEYWORDS}

Anal Fissure, Lateral Internal Sphincterotomy, Botulinum Toxin.

HOW TO CITE THIS ARTICLE: Ravindranath Singh, Puneet Pal Singh Oberoi, Nisith Kumar Ray. "A Study of Evaluation of Local Infiltration of Botulinum Toxin as Compared to Lateral Sphincterotomy in the Management of Chronic Anal Fissure.” Journal of Evolution of Medical and Dental Sciences 2015; Vol. 4, Issue 95, November 26; Page: 16057-16063,

DOI: $10.14260 /$ jemds/2015/2345.

Financial or Other, Competing Interest: None.

Submission 05-11-2015, Peer Review 06-11-2015,

Acceptance 18-11-2015, Published 25-11-2015.

Corresponding Author:

Dr. Ravindranath Singh,

2361, First C Main Road, Hampinagar,

Bengaluru-560104.

E-mail: navalursingh55@yahoo.com

DOI:10.14260/jemds/2015/2345.

\section{INTRODUCTION}

Chronic anal fissure is a common and distressing problem which occurs with equal frequency in men and women. The majority occur in the posterior midline below the dentate line extending up to the anal verge. Multiple or atypical locations are usually associated with chronic inflammatory bowel, venereal or immunodeficiency disease. 
The inciting event is usually the passage of hard stools with tear of the anal lining. Hypertonicity of the internal sphincter with consequent reduction in blood supply leads to relative ischemia and chronicity. ${ }^{1}$

Treatment over the centuries has evolved from conservative therapy with stool softeners and high fiber diet to surgical modalities comprising internal sphincter disruption. Both approaches aim to break the vicious cycle of pain and fear of defecation with consequent hard stools leading to further tear and spasm. Concern over uncontrolled or permanent sphincter damage along with better pharmacologic understanding has led to re-evolution of conservative approaches. Pharmacological/chemical sphincterotomy aim to temporarily relax the sphincter till healing is complete. Topical glyceryltrinitrate, calcium channel blockers and botulinum toxin A are the commonly employed agents.

Anal fissure is a disruption of the skin at the distal anal canal. Most anal fissures are located in the posterior midline, with $10 \%$ to $15 \%$ occurring anteriorly. "Off the midline" fissures must be viewed with suspicion for underlying pathology such as Crohn's disease, HIV/AIDS, tuberculosis, syphilis, or anal carcinoma. Early fissures have the appearance of a simple tear in the anoderm. With the passage of time, chronic fissures develop thickened skin margins and fibers of the Internal Anal Sphincter (IAS) become visible at the fissure's base. Many patients with chronic fissures develop a sentinel skin tag at the distal fissure margin and a hypertrophied anal papilla just proximal to the fissure within the anal canal. Anal fissure is a common disorder, but its exact incidence is unknown. The condition may frequently be misdiagnosed as hemorrhoids by primary care providers. The clinical hallmark of anal fissure is pain during, and especially after defecation.

The present study clinically assesses the role of botulinum toxin A in the management of chronic anal fissure (CAF). ${ }^{1}$ BTXs comprise a family of neurotoxins designated as types A to $\mathrm{G}$, which are produced by the anaerobic bacterium Clostridium botulinum. BTX-A blocks cholinergic transmission resulting in flaccid paralysis and autonomous nerve dysfunction. CAFs are caused by anal sphincter hypertonia leading to an ischemic ulcer. BTX-A injection into the internal or external anal sphincter causes relaxation of the anal sphincters, enhances microcirculation at the fissure site, and promotes fissure healing. Studies of BTX injection into the anal sphincter have reported excellent healing rates, although the procedure is more invasive, and patients may find it uncomfortable and less tolerable.

Brisinda et al. tried to optimize the dose of BTX. In their study, 150 patients with posterior AF were treated with BTX injected into the internal anal sphincter on each side of the anterior midline. Another study proved the use of local infiltration of BTX into the internal anal sphincter as an effective treatment for CAF. In a double-blind placebocontrolled study, 30 consecutive symptomatic adults were enrolled. ${ }^{2}$ Daniel et al. ${ }^{3}$ reviewed the published studies about the use of BTX injection in the management of chronic anal fissure. The authors reported that healing occurred in more than $70 \%$ of fissures without irreversible incontinence.

\section{DISCUSSION}

An anal fissure is a remarkably painful condition in an otherwise healthy population. The patient asks for relief, but is reluctant to accept the treatment that demands absence from day-to-day activities for a prolonged duration of time.

The exact cause of anal fissure is still unknown, but the precipitating factor is generally considered to be the trauma to the anal canal mucosa caused by hard stools. One factor that is important in causing anal fissure is chronic constipation. Once the fissure has established, spasms of internal sphincter prevents drainage and subsequent healing (Allan and May 1985) and is the basic cause of persistence of pain. Thus decreasing or inhibiting the contraction of internal anal sphincter should be mainstay of any treatment of anal fissure.

The treatment of anal fissure has undergone a continuous evolution during the past 50 years. Conservative management of the anal fissure has always been the initial treatment of choice and consists of stool softeners, sitz bath, high fiber diet and local anesthetic or analgesic ointments. However, this therapy is hardly documented in medical literature, but there have been studies on the efficacy of conservative therapy of anal fissure.

Fries and Rietz (1964). ${ }^{4}$ showed that $54.2 \%$ of patients were successfully treated on conservative line. Surgery has played an important role in the treatment of anal fissure. Fissurectomy was recommended by Gabriel (1930). ${ }^{5}$ Miles (1939). ${ }^{6}$ advocated pectinotomy later redesigned as internal sphincterotomy in 1951 by Eisenhammer. This posterior midline sphincterotomy has been criticized because of high incidence of minor defects of anal control, the key hole deformity and the protracted post-operative period as the fissures took on an average 7 weeks to heal.

Lateral subcutaneous internal sphincterotomy was introduced by Notaras (1969) and found that key hole deformity was eliminated, fissures healed within 3 weeks and the incidence of fecal soiling was only 6\%. Since 1969 there had been a number of studies on lateral subcutaneous internal sphincterotomy, e.g. Hawley (1969)56, Hoffmann and Goligher (1970). ${ }^{7}$ Notaras (1971). ${ }^{8}$ Miller (1971). ${ }^{9}$ Bailey et al. (1978). ${ }^{10}$ Abcarian (1980). ${ }^{11}$ Hsu et al. (1984). ${ }^{12}$ Pernikoff et al. (1994).13 They have all attested the superiority of this procedure over all other forms of surgery of anal fissure.

Anal dilation was probably originated with Recamier (1838). ${ }^{14}$ Its use was recommended by Goodsall. ${ }^{15}$ and later by Gabriel. ${ }^{16}$ at the end of the century. However, the main criticism of this procedure also has been the fairly large incidence of bruising and hematoma formation and problem of anal incontinence.

At present, the treatment of anal fissure depends upon the severity of the associated symptoms and the preference of treating physician. The treatment of choice even today in cases of longstanding and chronic fissure is some type of surgical intervention. This group also included cases with concomitant anal afflictions like hemorrhoids, fistulae or abscesses. All these patients are best treated by surgery, the procedure of choice depending on the individual patients.

At the end of the spectrum are patients with only minor symptoms, such as post defecation discomfort and bleeding 
where no great disability is present and who respond well to routine conservative treatment.

Between the two above mentioned extremes lies a large group of patients who experience severe symptoms and disability despite minor local findings. Attempted conservative treatment in such cases often fails to achieve immediate relief and the patients continue to suffer. If symptoms are severe despite the fact that local findings maybe may be minimal, these patients often become candidates for immediate surgical intervention. They often undergo either anal dilation or some form of sphincterotomy. In the majority of centers this involves hospitalization, use of general anesthesia, loss of days of work and the complications associated with surgical procedures such as reactionary hemorrhages, perianal abscesses with subsequent fistulae, prolapse of internal hemorrhoids and anal incontinence.

There have been efforts in the past to devise some form of therapy that does not necessitate surgical treatment, anesthesia or hospitalization, but significantly alleviates symptoms related to anal fissure.
Local injection into the internal anal sphincter of purified botulinum toxin has been suggested by various authors as a treatment modality in simple uncomplicated chronic anal fissure.

The present study was undertaken to assess the efficacy of Botulinum toxin type - A (BOTOX) in the treatment of simple chronic anal fissure. In the present study 60 cases of chronic anal fissures were treated. The cases were divided into 2 groups 30 patients underwent LIS (Lateral internal sphincterotomy) and 30 patients were injected with 5 units of Botulinum Toxin - A (BOTOX) into the internal anal sphincter.

\section{RESULTS}

Age and sex distribution of the patients. There were 42 male patients and 18 female patients in the study.

Thirty patient underwent lateral internal sphincterotomy and thirty patients were treated with Botunilum toxin.

The presenting complaints were pain, bleeding, spasm and incontinence in all patients. On per rectal examination, there was sphincter spasm noted in all patients.

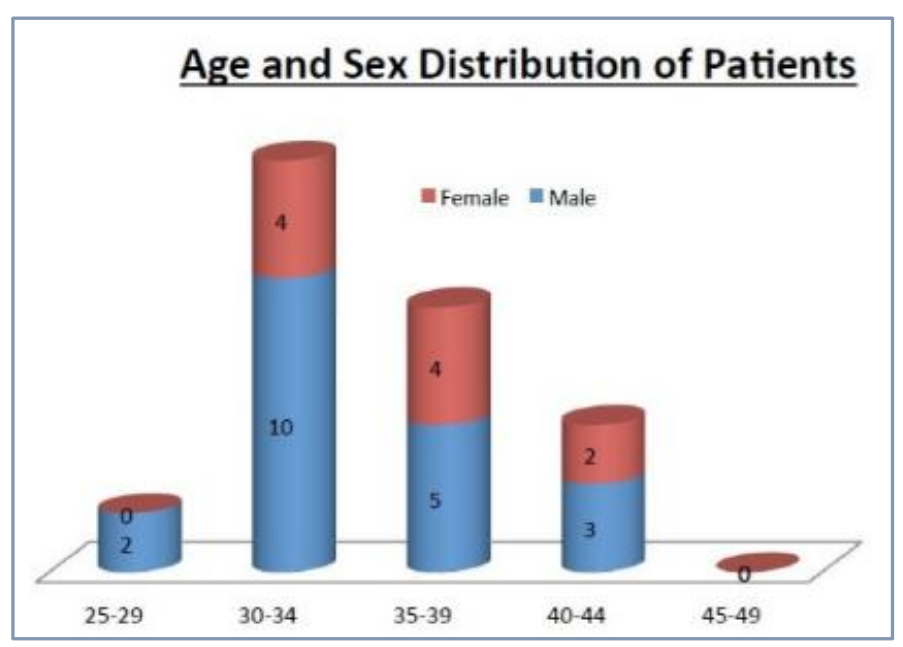

Chart 1: Patient Profile in Botulinum Toxin Arm of Therapy

\section{Botulinum Toxin Group:}

\begin{tabular}{|c|c|c|c|}
\hline Sl. No & Age in Years & Males & Females \\
\hline 1 & $25-29$ & 2 & 0 \\
\hline & & & \\
\hline 2 & $30-34$ & 10 & 4 \\
\hline 3 & $35-39$ & 5 & 4 \\
\hline 4 & $40-44$ & 3 & 2 \\
\hline 5 & $45-49$ & 0 & 0 \\
\hline \multicolumn{3}{|c|}{ Table 1: Age and Sex Distribution of Patients } \\
\hline \multicolumn{3}{|c}{} \\
\hline
\end{tabular}




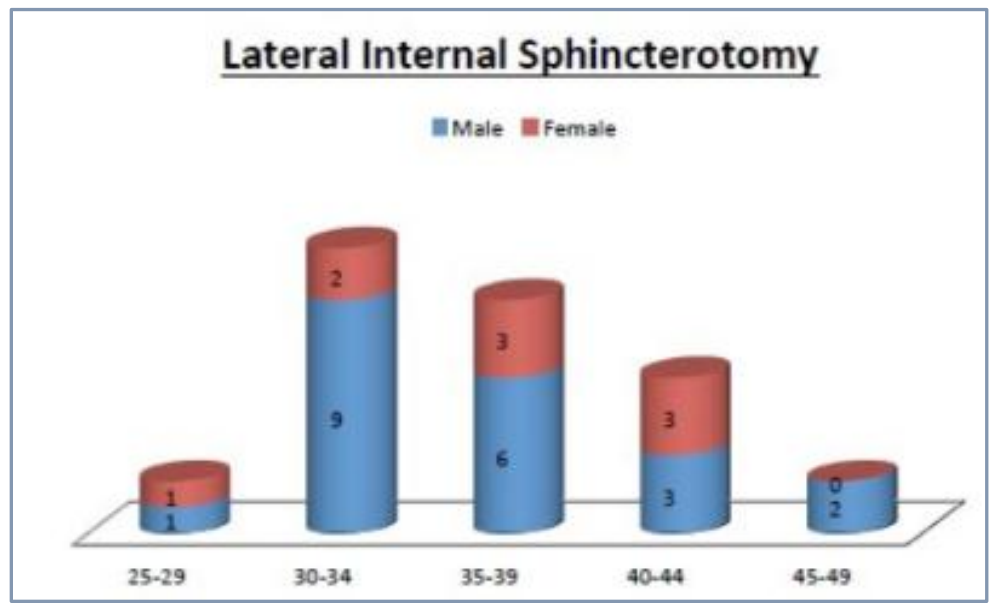

Chart 2: Patient Profile in Lateral

Sphincterotomy Arm of Therapy

From Analysis of this chart it is clear that:

Majority of the patients were in 30 to 40 year age group in both the treatment arms.

Males from the majority of patients in all age groups.

\begin{tabular}{|c|c|c|c|}
\hline Sl. No & Age in Years & Males & Females \\
\hline 1 & $25-29$ & 1 & 1 \\
\hline 2 & $30-34$ & 9 & 2 \\
\hline 3 & $35-39$ & 6 & 3 \\
\hline 4 & $40-44$ & 3 & 3 \\
\hline 5 & $45-49$ & 2 & 0 \\
\hline \multicolumn{3}{|c|}{ Table 2: Patient Profile of Lateral Sphincterotomy } \\
\hline
\end{tabular}

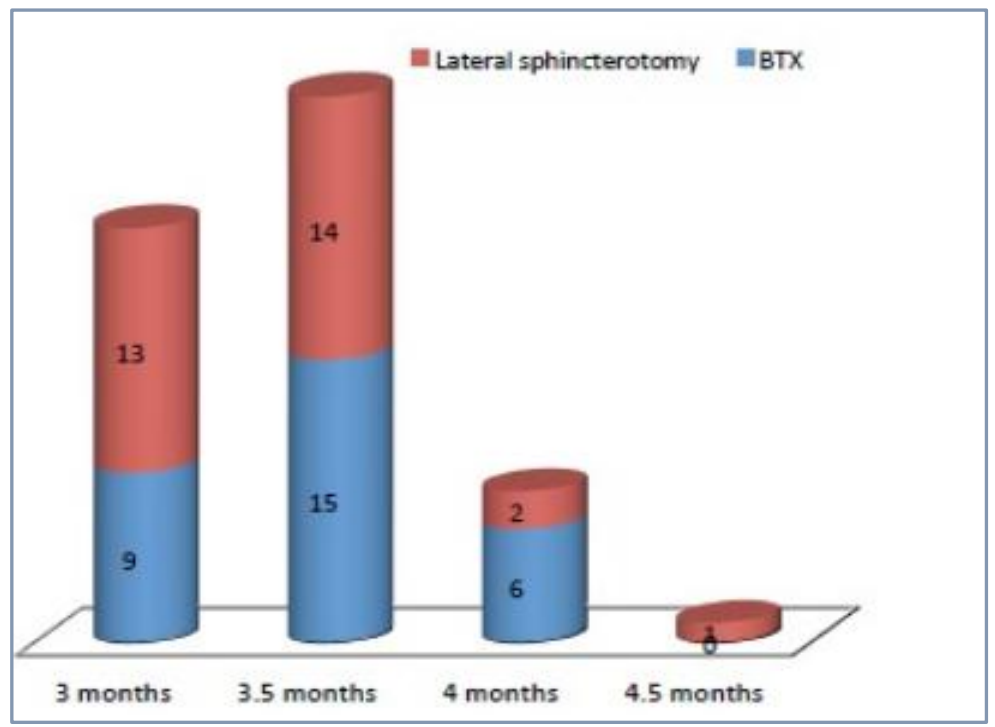

Chart 3: Comparison of Duration of Symptoms in Both the Modalities of Treatment

The Graph shows that the symptom duration of the patient included in both the treatment arms were similar. Thus there is matching of symptomatology in both the treatment arms.

The average duration of symptoms before presentation was 3.38 months.

\begin{tabular}{|c|c|c|}
\hline Duration & Botulinum Toxin & Lateral Sphincterotomy \\
\hline 3 Months & 9 & 13 \\
\hline 3.5 Months & 15 & 14 \\
\hline 4 Months & 6 & 2 \\
\hline 4.5 Months & 0 & 1 \\
\hline \multicolumn{2}{|c|}{ Table 3: Comparison of Duration of Symptoms } \\
in Both the Modalities of Treatment
\end{tabular}




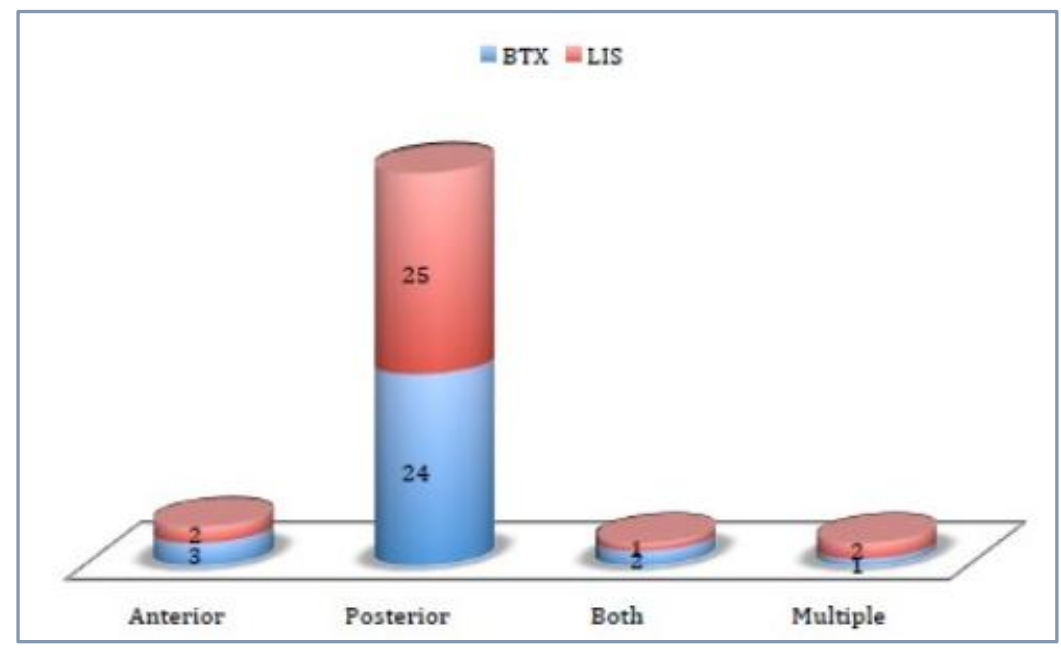

Chart 4: Analysis of Fissure Location

As shown in the above table majority number of patients had posterior midline fissures.

\begin{tabular}{|c|c|c|c|}
\hline Location of Fissure & BTX & LIS & TOTAL \\
\hline Anterior & 3 & 2 & 5 \\
\hline Posterior & 24 & 25 & 49 \\
\hline Both & 2 & 1 & 3 \\
\hline Multiple & 1 & 2 & 60 \\
\hline Total & 30 & 30 & \\
\hline \multicolumn{4}{|l}{ Table 4: Showing Analysis of Fissure Location } \\
\hline
\end{tabular}

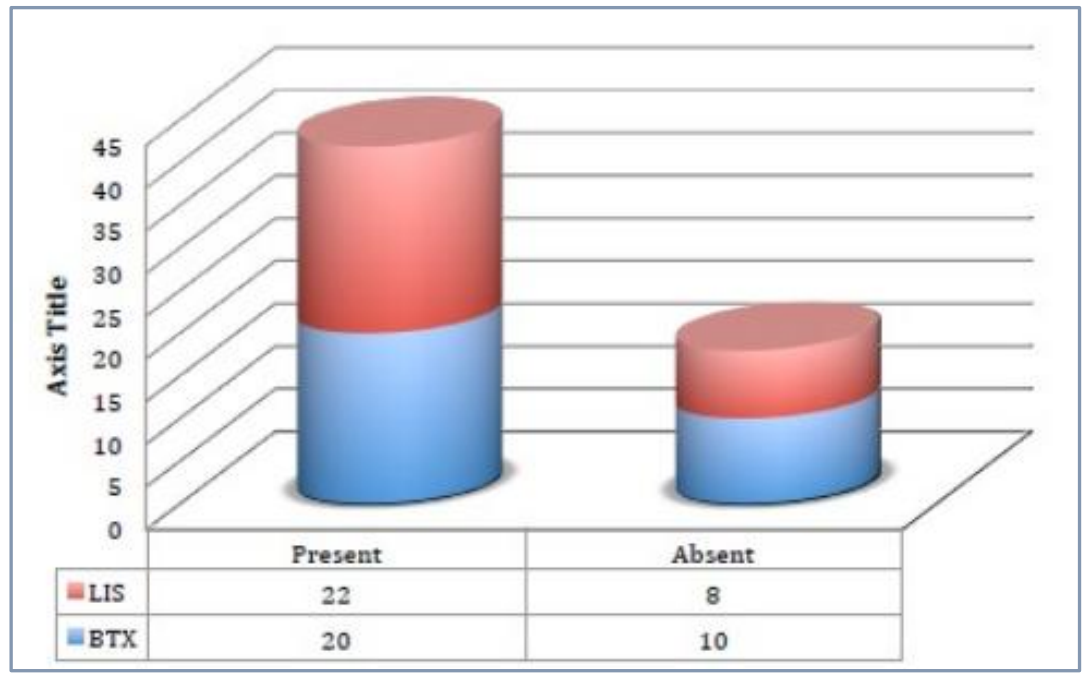

Chart 5: Showing Incidence of Sentinel Pile

The Sentinel Pile was present in majority of patients.

\begin{tabular}{|c|c|c|c|}
\hline Sentinel Pile & Study Group & Control Group & Total \\
\hline Present & 20 & 22 & 42 \\
\hline Absent & $\mathbf{1 0}$ & $\mathbf{8}$ & $\mathbf{1 8}$ \\
\hline Total & $\mathbf{3 0}$ & $\mathbf{3 0}$ & $\mathbf{6 0}$ \\
\hline \multicolumn{3}{|c|}{ Table 5: Showing Incidence of Sentinel Pile } \\
\hline
\end{tabular}

\begin{tabular}{|c|c|c|c|c|c|}
\hline $\begin{array}{c}\text { Treatment } \\
\text { Arm }\end{array}$ & $\begin{array}{c}\text { Pain Score } \\
(\mathbf{1 - 1 0})\end{array}$ & $\begin{array}{c}\text { Persistence } \\
\text { of Spasm }\end{array}$ & Bleeding & $\begin{array}{c}\text { No } \\
\text { Healing }\end{array}$ & Incontinence \\
\hline BTX $(\mathrm{n}=30)$ & $1( \pm 3.36)$ & 2 & 0 & 2 & 0 \\
\hline LIS(n=30) & $3( \pm 2.87)$ & 2 & 2 & 8 & 6 \\
\hline \multicolumn{6}{|c}{ Table 6: Comparison of Persistence of Complaints at 6 weeks } \\
\hline
\end{tabular}




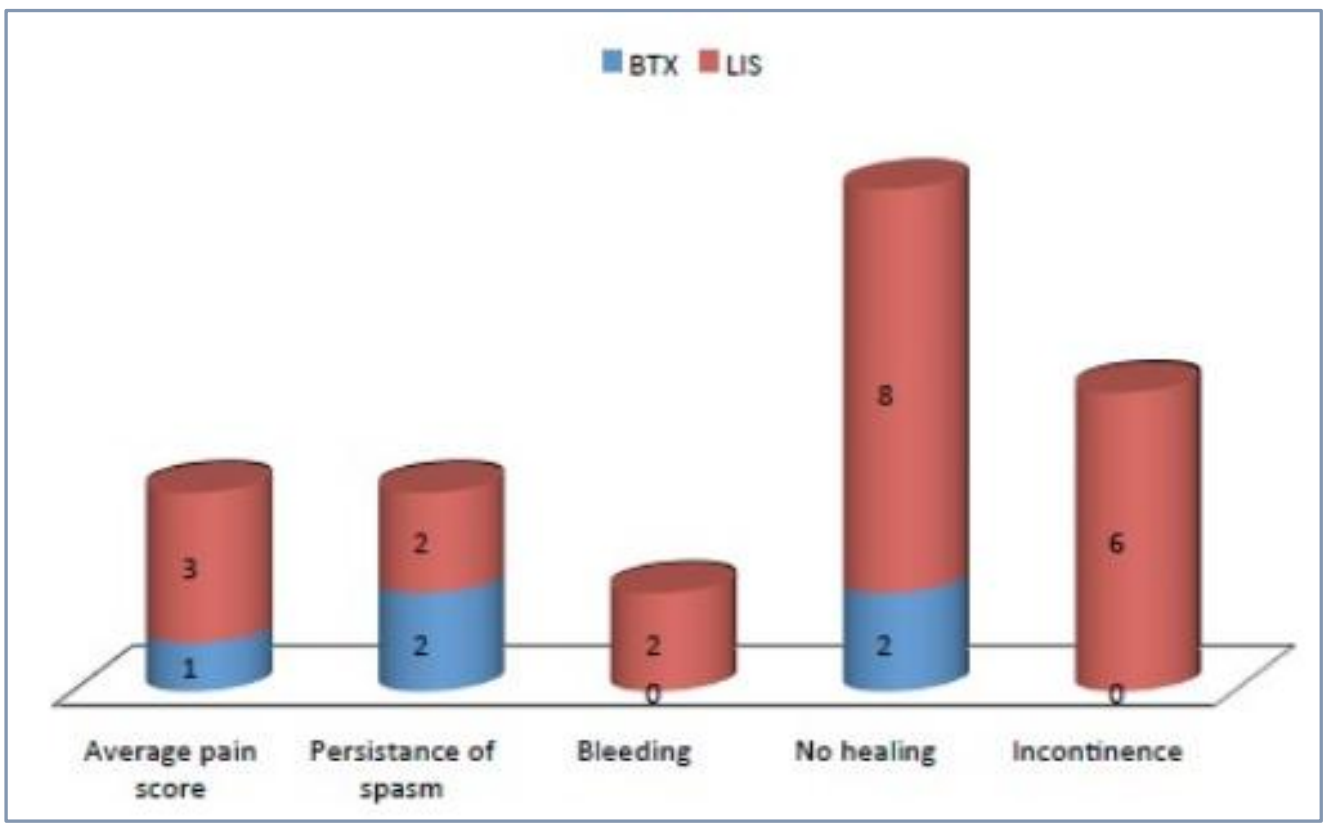

Chart 6: Comparison of Persistence of Complaints at 6 weeks

Statistical analysis: A Statistical analysis was performed on the variables as follows:

\begin{tabular}{|c|c|c|c|c|}
\hline & Number of Patients & Total Pain Score & Mean & Standard Deviation \\
\hline LIS & 30 & 93 & 3.1 & 0.3051 \\
\hline BTX & 30 & 33 & 1.1 & 0.3051 \\
\hline \multicolumn{4}{|c|}{ Fable-7: Comparison of Pain Scores Within the Two Groups } \\
\hline \multicolumn{4}{|c|}{} \\
\hline
\end{tabular}

Thus from the Table it is clear that relief in the pain is significantly better with BTX Infiltration than with LIS.

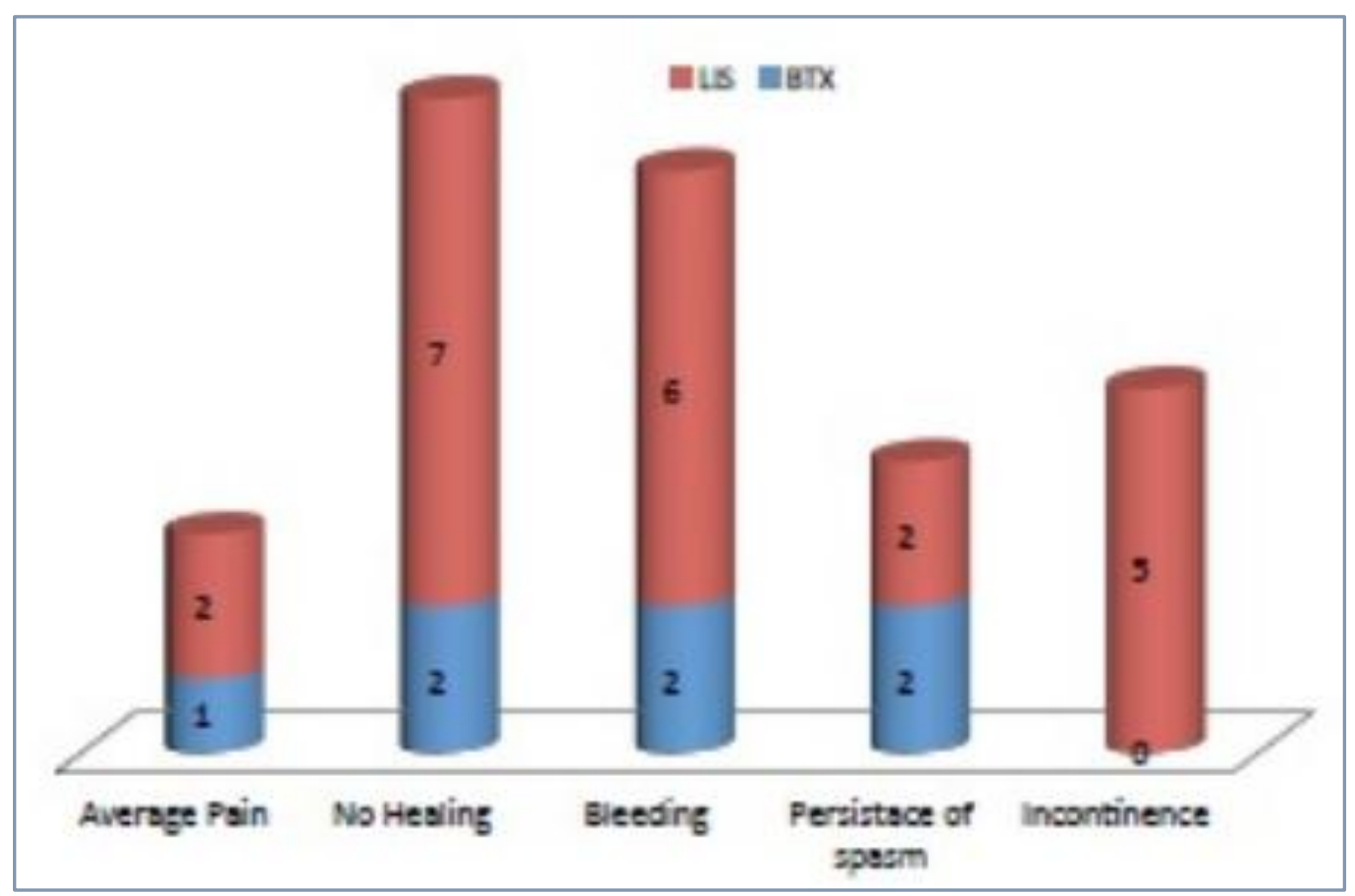

Chart 7: Comparison of Persistence of Complaints at 6 Months

Pain Relief was significantly better with LIS in the BTX Group even at 6-month duration. With respect to bleeding, there was substantial bleeding in LIS treatment arm. 


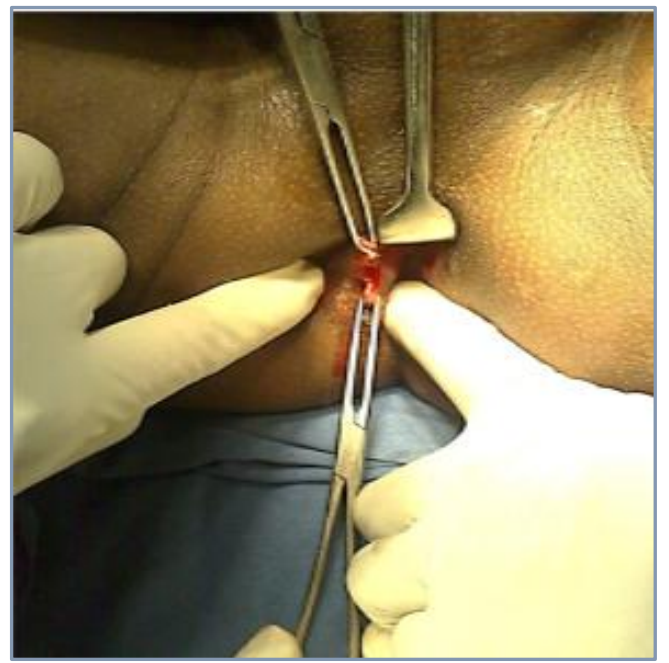

Fig. 1: Lateral Sphincterotomy Being Done

\section{CONCLUSION}

From this study, it was concluded that surgery required hospitalization and period off work. There was also present the risk of complications of general or spinal anaesthesia. Moreover, no hospital stay was required in cases treated by injection of 5 units of botulinum toxin. It is a painless, nonsurgical procedure giving relief of symptoms to the patients in a simple way with no blood loss of operative procedure, no anaesthesia required, no operative trauma, domicillary treatment and negligible chance of side effects. Thus injection of botulinum toxin hold quite a good promise in the future when compared to other forms of treatment modalities and can be used as a treatment of choice in patients unfit for surgery or patients having high risk of anaesthetic complications.

\section{BIBLIOGRAPHY}

1. Bhardwaj R, Parker MC. Modern perspectives in the treatment of chronic anal fissures. Ann R Coll Surg Engl 2007;89:472-8.

2. Maria G, Cassetta E, Gui D, et al. A comparison of botulinum toxin and saline for the treatment of chronic anal fissure. N Engl J Med 1998;338:217-20.

3. Daniel F, De Parades V, Siproudhis L, et al. Botulinum toxin and chronic anal fissure. Gastroenterol Clin Biol 2006;30:687-95.

4. Fries B and Rietz KA. Treatment of fissure in ano. Acta Chirurgica Scandi navica 1964;128:312-15.

5. Gabriel W B 1945. The principles and practice of rectal surgery. Lewis: London.

6. Miles WE. Observation upon internal piles. Surg Gynccol Obstet 1923;29:497.506.

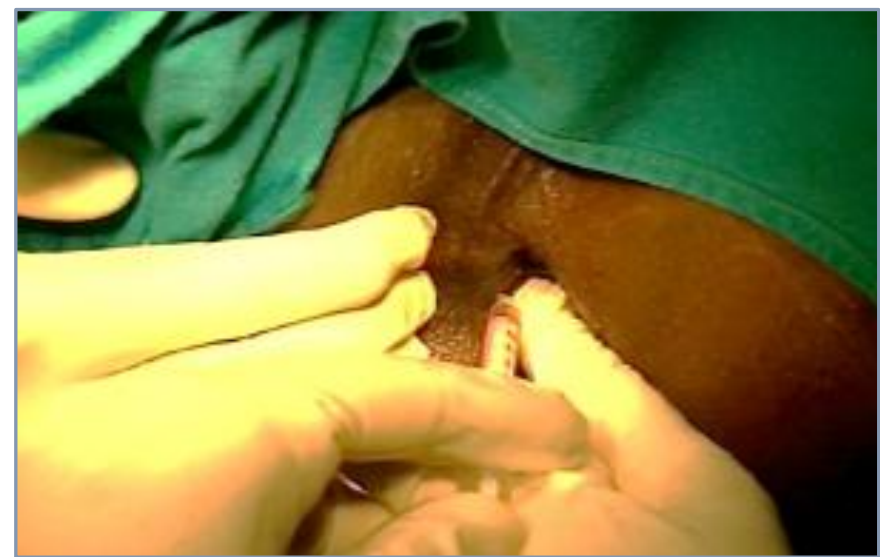

Fig. 2: BOTOX Injection Being Given

7. Morgan CN and Thompson HR (1956). Quoted by Hoffmann DC and Goligher JC. BMJ; 673-75.

8. Martin EG (1923). Quoted by Notaras MJ. Trearmem of anal fissure by lateral subcutaneous internal sphincterotomy- A technique and results. Br J Surg 1971;58:96.

9. Miller DM. Subcutaneous lateral internal sphincterotomy for anal fissure. Br J Surg 1971;58:737.

10. Bailey HR, Beck DE, Billingham RP, et al. A study to determine the nitroglycerin ointment dose and dosing interval that best promote the healing of chronic anal fissures. Aliment Pharmacol Ther 2002Jan;16(1):101-3.

11. Abcarian H. Surgical correction of chronic anal fissure: results of lateral internal sphincterotomy. Dis Colon Rectum 1980;23:31-36.

12. Hsu TC and Mackeigan JM. Surgical treatment of chronic anal fissure: A retrospective study of 1753 cases. Dis Col Rectum 1984;27:75-78.

13. Pernikoff BJ, Eisenstat TE, Rubin RJ, Oliver GC and Salvati EP. Reappraisal of partial lateral internal sphincterotomy. Dis Colon Rectum 1994;37:1291-5.

14. Recamier JCA (1829). Quoted by Goodsall DH, Mliles WE in Diseases of the anus and rectum. Part I Longmans, 1990.

15. Goodsall DH and Miles WE (1900). Quoted by Lock MR and James PS Thomson Fissure in ano: The initial management and prognosis. Br J Surg 1977-64. 355-58.

16. Gabriel W B 1945. The principles and practice of rectal surgery. Lewis: London. 